\title{
Iron Nanoparticle Composite Hydrogels for Studying Effects of Iron Ion Release on Red Blood Cell In Vitro Production
}

\author{
Katharina Brändle, Timna C. Bergmann, Annamarija Raic, Yaya Li, Nina Million, Christoph Rehbock, \\ Stephan Barcikowski, and Cornelia Lee-Thedieck*
}

\begin{abstract}
Growing numbers of complex surgical interventions increase the need for blood transfusions, which cannot be fulfilled by the number of donors. Therefore, the interest in producing erythrocytes from their precursors-the hematopoietic stem and progenitor cells (HSPCs) - in laboratories is rising. To enable this, in vitro systems are needed, which allow analysis of the effects of essential factors such as iron on erythroid development. For this purpose, iron ion releasing systems based on poly(ethylene glycol) (PEG)-iron nanocomposites are developed to assess if gradual iron release improves iron bioavailability during in vitro erythroid differentiation. The nanocomposites are synthesized using surfactant free pulsed laser ablation of iron directly in the PEG solution. The iron concentrations released from the material are sufficient to influence in vitro erythropoiesis. In this way, the production of erythroid cells cultured on flat PEGiron nanocomposite hydrogel pads can be enhanced. In contrast, erythroid differentiation is not enhanced in the biomimetic macroporous $3 \mathrm{D}$ composite scaffolds, possibly because of local iron overload within the pores of the system. In conclusion, the developed iron

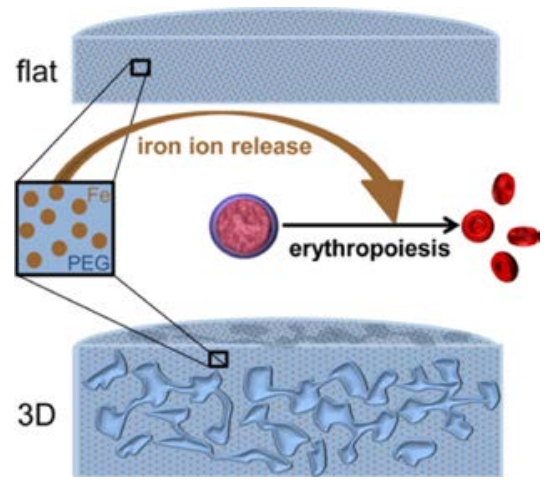
nanoparticle PEG composite hydrogel allows constant iron ion release and thus paves the way (i) to understand the role of iron during erythropoiesis and (ii) toward the development of biomaterials with a controlled iron release for directing erythropoiesis in culture.
\end{abstract}

KEYWORDS: iron nanoparticle, hydrogel, hematopoietic stem cell, erythropoiesis, red blood cell production, iron release system, regenerative medicine, stem cells

\section{INTRODUCTION}

Blood transfusions are indispensable in emergency medical treatments, therapy of chronic diseases, or for the support of advanced surgical procedures. ${ }^{1,2}$ Supplying this demand can only be facilitated by a sufficient number of donations from donors covering the whole spectrum of blood types. Although it sounds simple considering that a blood donation can be easily applied, so far it is unfeasible because of several obstacles. Aging populations in western societies or shortage of medical institutions in developing countries, hosting around $80 \%$ of the world's population, result in low donation rates. 3,4 This leads to a critical deficiency of blood products especially for patients with under represented blood groups. Further more, impurities including infectious contaminations of the products make them useless in some cases. The storage time of useable blood products is limited, which triggers the need for more blood. 5,6 To meet this demand, research has been increasingly focused on "blood farming".

"Blood farming" means the in vitro production of blood cells via targeted differentiation from stem cells. The generation of erythrocytes is of utmost importance because they are the most frequent cell type and oxygen supplier of the bloodstream, which contributes to the maintenance of homeostasis of all tissues. Erythrocytes are formed during hematopoiesis from HSPCs in a hierarchical differentiation process via a multitude of erythroid precursor cells and are characterized by the expression of certain markers. ${ }^{8,9}$ Early progenitors express CD71, with progressing development CD235 is expressed additionally and in the final maturation stages (erythroblasts to erythrocytes) CD71 expression gets lost, while CD235 is still expressed.9 Because of the availability of HSPCs from umbilical cord blood donors, the production of blood in an in vitro culture originating from HSPCs is a promising tool to apply in "blood farming" and thereby provide safe blood products for several patients from a single donor. ${ }^{10-13}$

In order to implement this, strategies for in vitro erythroid expansion were developed in the last few years. In vitro cultures of HSPCs are stimulated with organic growth factors such as erythropoietin, hydrocortisone, or a feeder layer of cells to 
trigger their proliferation and initiate erythropoiesis. To increase the outcome of erythropoiesis, erythroid differ entiation can also be transferred to a stirred micro bioreactor ensuring sufficient nutrient consumption. However, there is still ongoing research aiming at an increased yield and finding new erythroid stimulating factors. ${ }^{14}$ In the field of tissue engineering, a trend toward 3D cell culture environments resembling the in vivo conditions has been observed because biomimetic scaffolds showed promising results in HSPC culture and helped in guiding their differentiation. ${ }^{15-17}$ Cell aggregates in a porous structure mimicking the in vivo bone marrow led to a large red blood cell production ${ }^{16}$ and $3 \mathrm{D}$ scaffolds from synthetic polymers support the generation of early erythroid progenitors from HSPCs. ${ }^{19}$ Moreover, functionalization of $3 \mathrm{D}$ scaffolds with activated $\mathrm{BM}(\mathrm{PEG}) 2$ ( 1,8 bismaleimido diethyleneglycol) was shown to enhance the proliferation of $\mathrm{CD} 34^{+}$and erythroid progenitor cells. ${ }^{18}$

The oxygen transport function of mature erythrocytes depends on hemoglobin, which is synthesized by erythrocyte progenitors during differentiation. Hemoglobin contains 4 heme groups with coordinately bound central $\mathrm{Fe}^{2+}$, which are responsible for oxygen binding and release. ${ }^{19,20}$ Transfer of the iron ions into the maturing cells is enabled by apotransferrin which corresponds to transferrin when bound to iron. It was shown that this inorganic substance (nontransferrin bound iron ions) in a certain concentration had a positive effect on HSPC differentiation into erythrocytes. ${ }^{21}$ When bound to transferrin, iron ions can enhance erythropoiesis with increasing transferrin concentrations. ${ }^{22}$ However, the beneficial effects of iron ions on erythropoiesis depend on the concentration, as high amounts of iron ions are cytotoxic. All in all, iron ions seem to play an important role in the formation of functional erythrocytes, as their function depends on the successful production of hemoglobin with incorporated iron ions by erythroid progenitor cells. As mature erythrocytes have no nuclei, hemoglobin production has to be accomplished during differentiation in the progenitor cells and cannot take place in mature cells. Therefore, identifying the influence of iron ions on erythrocyte differentiation will help us to elucidate if and how iron could be used to control in vitro erythropoiesis for blood farming approaches. Instead of spiking the entire medium with iron ions, the utilization of iron nanoparticles could be a promising alternative. Such nanoparticles might serve as depots for iron ions released in the particles' vicinity, while keeping the overall iron concentration low. This may help to minimize the potential adverse effects of soluble iron on cell viability because of iron overload in culture. This concept was previously utilized in iron nanoparticle alginate gel composites, where a local increase in iron ion concentration and not the overall dose were considered responsible for the biological effect. ${ }^{23}$ Free iron or iron oxide nanoparticles can penetrate the cell membrane because of their very small size, they have potential toxic side effects, for example, by oxidative damage of cellular components that can ultimately lead to apoptosis. ${ }^{24}$ Therefore, using the iron releasing nanoparticles as a composite by integrating them in a suitable cell culture substrate such as hydrogels is favorable.

The current state of the art in synthesizing nanoparticle composites is a labor intensive process. Nanoparticles are first generated by wet chemistry reduction of precursors in the presence of potentially toxic stabilizing ligands. In a consecutive step, the nanoparticles are embedded into the polymer matrix, which often requires matrix coupling reagents. ${ }^{25}$ As an alternative approach, pulsed laser ablation in liquids (PLAL), for the fabrication of the corresponding nanocomposites is highly promising. ${ }^{23,26}$ This method has been intensively studied and is based on the irradiation of bulk metal targets by pulsed lasers in liquid yielding colloidal nanoparticles. ${ }^{27,28}$ When PLAL is carried out directly in a monomer solution (in situ), the generated nanoparticles immediately interact with the monomers, which stabilize the particles and enable monodisperse particles with mean diameters $<10 \mathrm{~nm}^{29}$ In a consecutive step, the monomers can be subjected to polymerization, for example, by UV light irradiation. For hydrogel nanocomposite synthesis, even this step is obsolete, as the nanoparticles are directly synthesized by PLAL in the aqueous hydrogel solution. ${ }^{23}$ This synthesis route is a well suited approach for the controlled fabrication of rationally designed nanocomposites and has a number of striking advantages in contrast to chemical synthesis: (I) Purity: As the nanoparticles can be generated in the monomer solution without the use of additional stabilizing ligands or precursors, potential toxic side effects from additives can be excluded. (II) Stability: The generated nanoparticles directly interact with the monomers prior to polymerization. Hence, they show an excellent matrix coupling, which prevents aggregation and omits the use of matrix coupling agents. ${ }^{30}$ Homogeneous particle size distributions are retained even upon polymer processing such as injection moulding, ${ }^{30}$ electrospinning, ${ }^{31}$ or $3 \mathrm{D}$ bioextrusion. ${ }^{23}$ (III) Easiness and scalability: In comparison to chemical synthesis, where new formulations are required for every embedded nanoparticle type, in this approach different materials can be mixed, simply by changing the ablated targets, yielding multicomponent composites termed "nanococktails". ${ }^{32}$ The embedded nano particle mass can be altered by the ablation time and can be quantified by simply weighing the bulk target prior to and after ablation. The process is scalable in a $\mathrm{g} / \mathrm{h}$ regime concerning nanoparticle production, ${ }^{33}$ yielding $\mathrm{kg} / \mathrm{h}$ scales in the case nanoparticles with a load of $0.1 \mathrm{wt} \%$ are embedded into the composite. Previous results of the authors based on PLAL could conclusively show that thermoplastic polyurethane (TPU) nanocomposites containing noble metal nanoparticles ( $\mathrm{Au}$ and $\mathrm{Pt}$ ) could enhance the adhesion of fibroblasts in comparison to unloaded TPU, probably due to increased surface hydrophilicity. ${ }^{34}$ On the other hand, embedding of iron (oxide) nanoparticles into hydrophilic alginate gels resulted in an enhanced cellular adhesion, while Au nanoparticles had no effect. In this case, we concluded that the release of iron ions is the main discriminator influencing cellular adhesion on bioextruded hydrogels. ${ }^{23}$

The aim of the present study was to develop an in vitro system, which allows a constant iron ion release from a cytocompatible iron nanoparticle composite material and to use it to investigate the influence of iron on HSPC differentiation into erythrocytes. For this purpose, first, an iron nanoparticle (PEG) composite hydrogel was synthesized, characterized, and its capacity to influence erythroid differ entiation was demonstrated. In a second step, the hydrogel was further developed into an iron ion releasing, 3D biomimetic scaffold mimicking the porous structure of trabecular bonethe region of bone where the red bone marrow is found, and thus erythropoiesis takes place naturally. The results of this study pave the way for using iron ions released from the composite material scaffolds to direct in vitro erythropoiesis for "blood farming". 

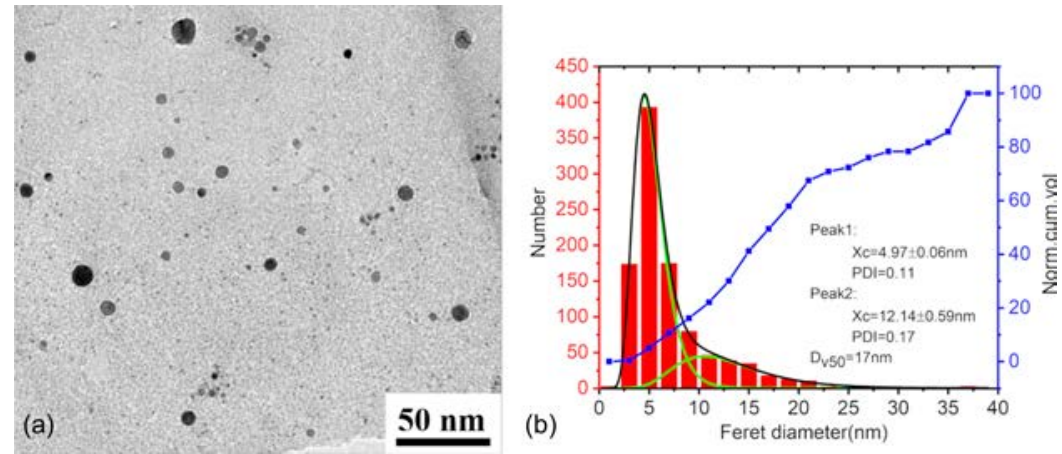

Figure 1. Characterization of laser generated iron nanoparticles. Representative TEM images of iron nanoparticles $(0.012$ wt $\%)$ generated by laser ablation in PEG DA/MA solution (a). Number weighted iron nanoparticle size distributions were derived from TEM images with two log normal fitting peaks (black and green lines) and calculated PDI (b). The number of particles (red) mainly covers an average of around $5 \mathrm{~nm}$. The volume weighted size distribution function is represented by the cumulative curve (blue).
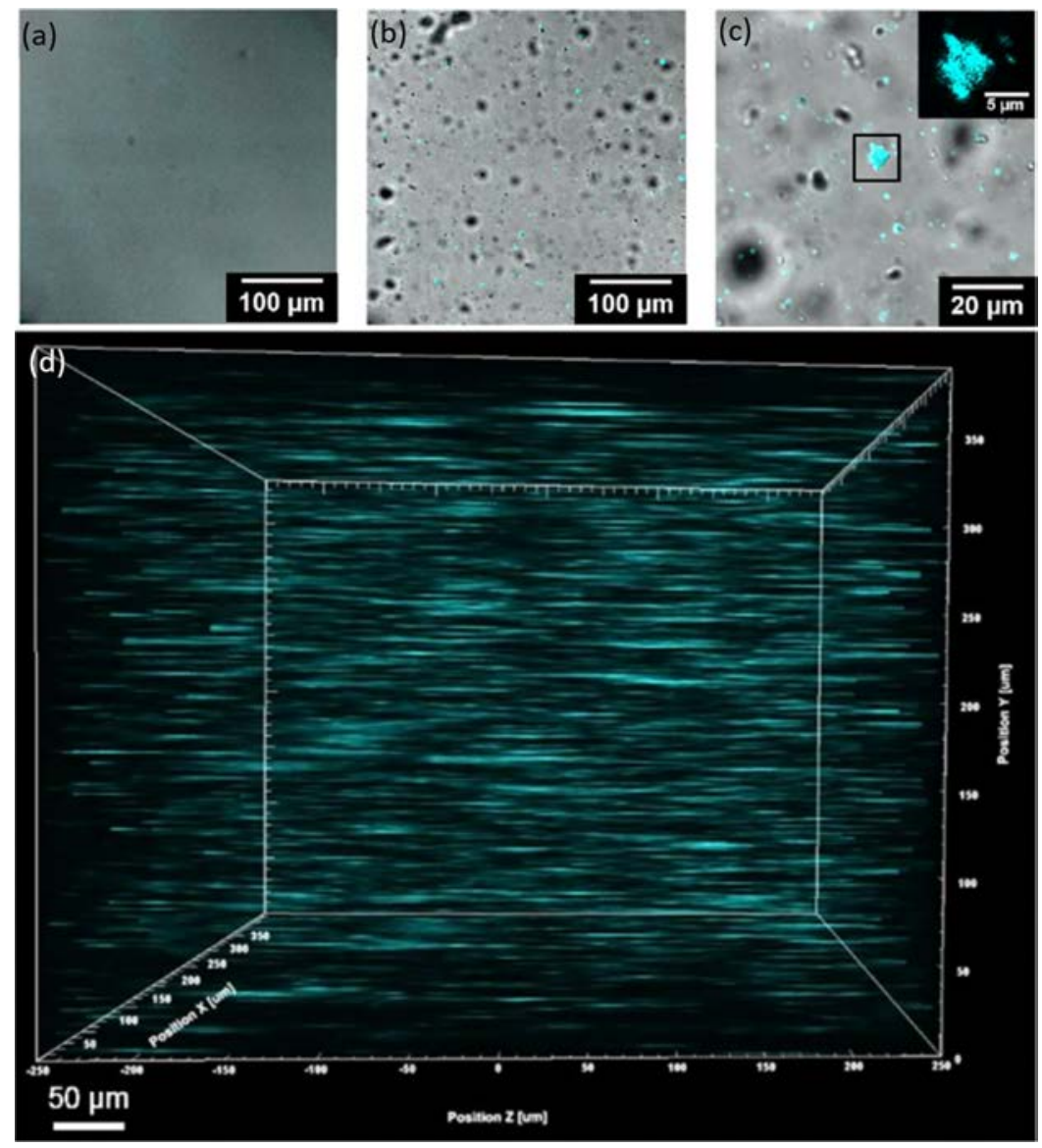

Figure 2. CLSM images of hydrogels with and without embedded iron nanoparticles (0.012 wt \%). In (a) images of blank PEG DA/MA hydrogels without particles and in $(b, c)$ images of iron nanoparticle loaded PEG DA/MA hydrogels are shown. (c) indicates images of hydrogel embedded nanoparticles at higher magnification. (d) Nanoparticle distribution in a 3D total scan of a hydrogel revealing homogeneous distribution.

\section{RESULTS}

Nanoparticle Characterization. In an initial stage, iron nanoparticles that were laser ablated in the presence of a PEG DA/MA solution were characterized by transmission electron microscopy (TEM) (Figure 1). Iron nanoparticles revealed a uniform spherical morphology. The corresponding particle number weighted diameter distributions were analyzed from the TEM images. They show that the peak of the spherical particle size distribution was at around $5 \mathrm{~nm}$ and a tail extending up to $\sim 25 \mathrm{~nm}$ was found. It is worth noting that two fitting peaks showed $X_{\mathrm{c}}=4.97 \mathrm{~nm}(\mathrm{PDI}=0.11)$ and $X_{\mathrm{c}}=$ $12.14 \mathrm{~nm}(\mathrm{PDI}=0.17)$, which indicated the narrow particle size distributions. ${ }^{35}$ In the TEM images, one can clearly identify that the iron particles do not form aggregates (usually indicated by solid-solid bridges), even though particle agglomeration (characterized by particles loosely bound by van der Waals and electrostatic forces) can be frequently found. This good dispersion of particles is expected, if PLAL is applied in aqueous macromolecule solutions, as the hydrogels' molecules contribute to the nanoparticles' steric stabiliza tion. ${ }^{27,28}$ Please note that the TEM images show particles of 
(a)
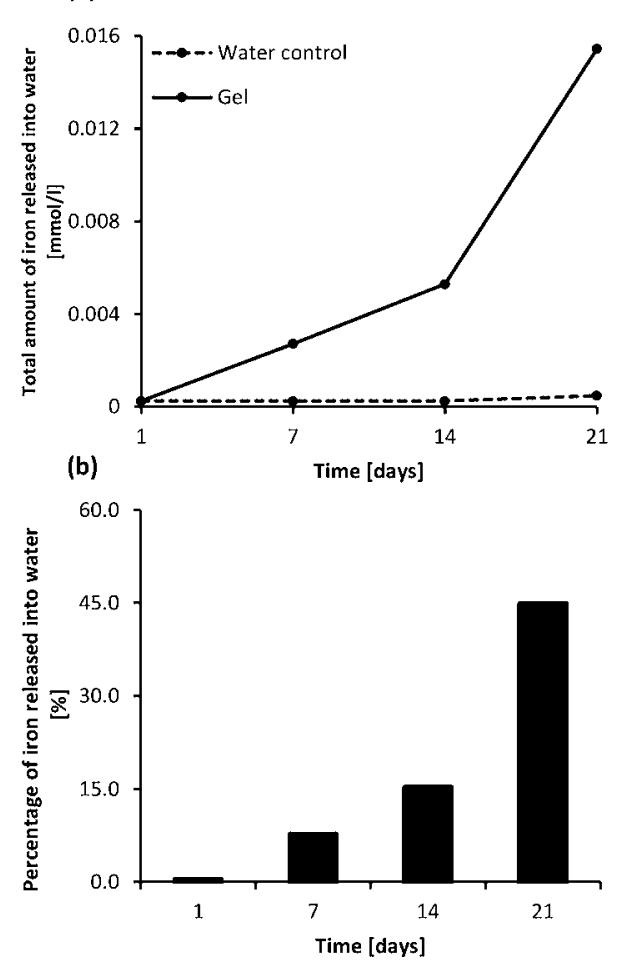

(c)
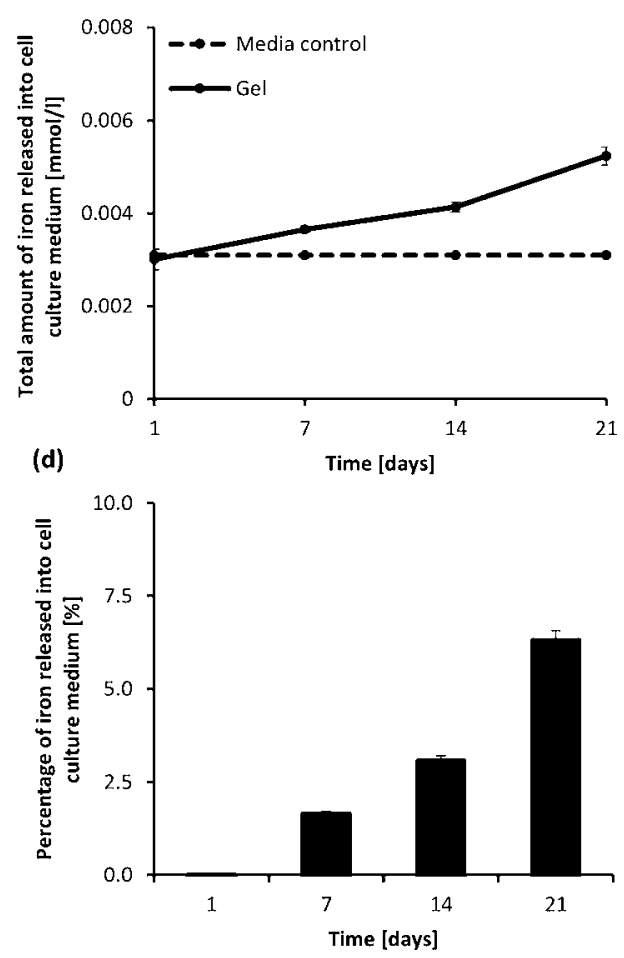

Figure 3. Iron release studies from the iron nanoparticle composite hydrogels in water and medium. The iron ion release (solid line) from flat hydrogel pads containing iron nanoparticles was measured in $2.2 \mathrm{~mL}$ of water $(\mathrm{a}, \mathrm{b})$ and cell culture medium $(\mathrm{c}, \mathrm{d})$ over a time period of 21 days. As a control (a,c: dotted line), hydrogels without iron nanoparticles were used. The percentage of released iron from the flat hydrogel pads into the water and cell culture media was measured over a time period of 21 days $(\mathrm{b}, \mathrm{d})$. Error bars represent the SD of two samples and are too small to be visible for the iron release in water [(a) SD $\leq 0.00005 \mathrm{mmol} / \mathrm{L}$, (b) SD $\leq 0.07 \%$ ].

the same size but with highly different brightness. This is a well documented phenomenon in TEM and probably associated to the fact that the brightness of even a perfect crystal nanoparticle can differ in TEM because of the orientation toward the electron beam. The particles which appear darkest probably have strong diffraction with crystal planes oriented almost parallel to the electron beam. This phenomenon was previously reported in experimental studies, for example, for silicon nanoparticles ${ }^{36}$ but also further explained by simulations of HR TEM images of metal nanoparticles at different tilting angles. ${ }^{37}$

Flat Hydrogel Pads. Hydrogels with variable nanoparticle loadings were synthesized. The samples were further characterized by confocal laser scanning microscopy (CLSM) of hydrogels produced from these solutions (Figure 2). The CLSM dark field microscopy images clearly revealed an even distribution of nanoparticles within the matrix, further backed by a $3 \mathrm{D}$ image of the entire hydrogel, scanned in $1 \mu \mathrm{m}$ steps. Images of a pure PEG DA/MA gel pads without nanoparticles were used as a reference (Figure 2a). In these images of unloaded PEG DA/MA gels, no positive signals were recognizable, while the signals obtained for the iron nano particle loaded gels can be clearly assigned to nanoparticles (Figure $2 \mathrm{~b}, \mathrm{c}$ ). It should be noted that only nanoparticles with particle sizes $>60 \mathrm{~nm}$ can be resolved by this technique. ${ }^{38}$ Smaller structures are only detectable as single spots, which may differ in intensity based on the number of single particles within an agglomerate. As previously shown by TEM images, a fraction of the iron nanoparticles was also present as agglomerates. The overview image clearly revealed that there were agglomerates of about $225 \mathrm{~nm}$. A total scan of the gel showed that the nanoparticles or their agglomerates are homogeneously distributed throughout the $3 \mathrm{D}$ gel matrix (Figure 2d).

For using the developed flat hydrogel pads with iron nanoparticles in cell culture the content of iron nanoparticles in the hydrogel, as well as the iron release in solution, were measured to determine the iron concentration available for cells.

In the flat hydrogel pads containing $0.012 \%(\mathrm{w} / \mathrm{v})$ iron nanoparticles, $4.17 \pm 0.10 \mu \mathrm{g}$ iron/gel was measured. The release of iron from the composite hydrogels and control gels (without iron) were measured in water by inductively coupled plasma optical emission spectrometry (ICP OES) at days 1, 7, 14, and 21 (Figure 3).

The iron concentration released from the nanocomposite into water showed a linear increase with time. After 21 days of incubation, the iron content in water reached a maximum total amount of $0.86 \pm 0.003 \mu \mathrm{g} / \mathrm{mL}$, corresponding to an iron concentration of $0.015 \pm 0.00005 \mathrm{mmol} / \mathrm{L}$. Thus, $44 \%$ of the iron mass in the hydrogel was released to water during the incubation time (Figure $3 \mathrm{~b}$ ). In medium, the iron release was 3 fold lower than in water and after 21 days a maximum total amount of $0.29 \pm 0.01 \mu \mathrm{g} / \mathrm{mL}(0.005 \pm 0.00019 \mathrm{mmol} / \mathrm{L})$ was reached (Figure $3 \mathrm{c}$ ), corresponding to an approximate iron release of $0.014 \mu \mathrm{g} / \mathrm{mL}(0.00024 \mathrm{mmol} / \mathrm{L})$ per day. The basal iron concentration in the applied cell culture media was found to be $0.003 \mathrm{mmol} / \mathrm{L}$. This means that $6.3 \%$ of the iron in the hydrogel was released to the medium (Figure $3 \mathrm{~d}$ ). In both control gels, no increase of the iron concentration could be detected. In summary, we could show a constant release of iron ions from the iron nanoparticle composite hydrogels both into 
(a)

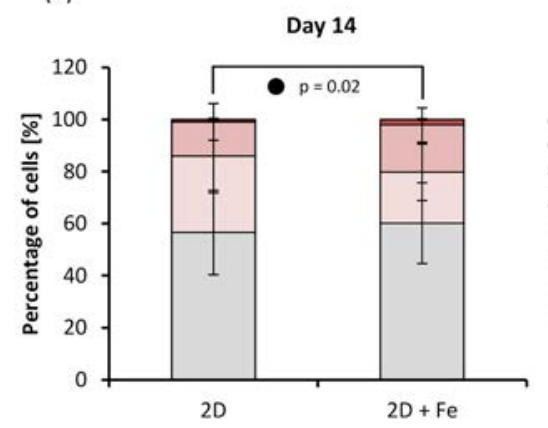

(b)

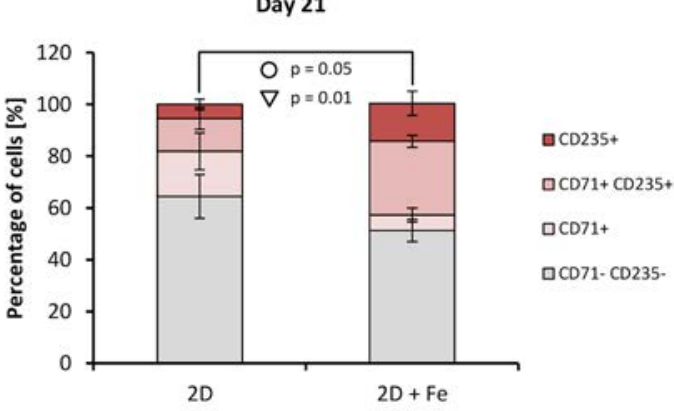

- significant difference in \% of CD71+ cells $\nabla$ significant difference in \% of CD71+CD235+ cells O significant difference in \% of CD235+ cells

Figure 4. Percentage of erythroid progenitors on iron nanoparticle composite hydrogels. (a) After 14 days of culture (left) on hydrogels without iron nanoparticles (left bar) and with iron nanoparticles ( $0.012 \mathrm{wt} \%)$ (right bar), the percentage of CD71 ${ }^{+}$cells (early erythroid progenitors), $\mathrm{CD} 1^{+}, \mathrm{CD}_{235^{+}}$(more committed progenitors), or CD235 (late erythroid progenitors and/or mature erythrocytes) were analyzed. (b) The diagram on the right shows the result of the analysis after 21 days of culture on hydrogels without (left bar) and with iron nanoparticles (right bar). The error bars represent the SE. $N=4$ independent experiments.

(a)

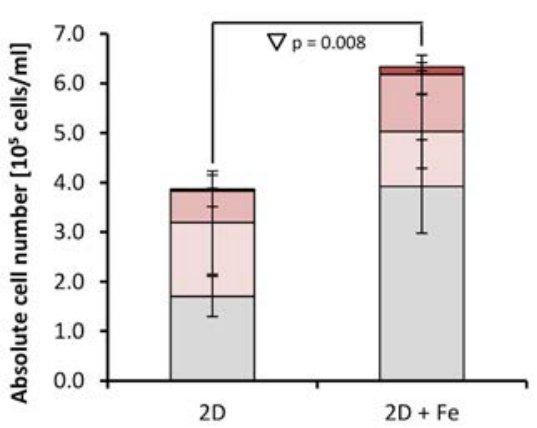

(b)

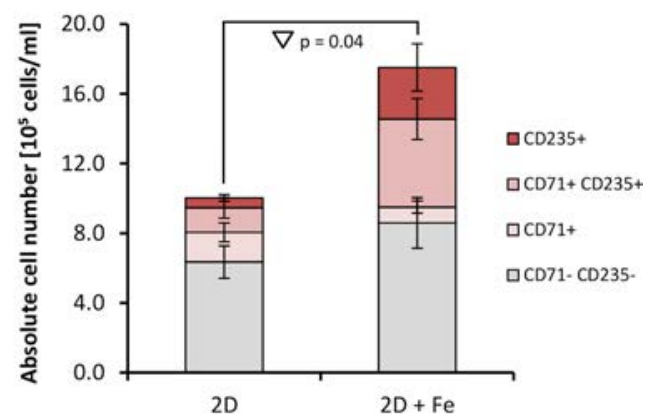

$\nabla$ significant difference between the total numbers of $\mathrm{CD} 71+\mathrm{CD} 235+$ cells

Figure 5. Absolute cell numbers of erythroid progenitor cells on flat iron nanoparticle composite hydrogel pads. (a) Absolute cell number of erythroid progenitor cells on hydrogels without (left bar) and with (right bar) iron nanoparticles (0.012 wt \%) after 14 days of culture. (b) After 21 days of culture, the absolute number of cells is plotted in the right graph. The error bars represent the SE. $N=4$ independent experiments.

the supernatant water and cell culture medium from the flat hydrogel pads.

To assess whether the amount of released iron was sufficient to influence erythroid differentiation, expansion and differ entiation media were spiked with iron concentration in the concentration range of the daily iron release from the developed hydrogels. A significant increase of the $\mathrm{CD}_{7} 1^{+}$/ $\mathrm{CD}_{235 \mathrm{a}^{+}}$population after 21 days of culture in iron supplemented medium could be observed (Figure S1).

The developed iron nanoparticle composite hydrogels were used to study the effect of constant iron release on erythropoiesis of freshly isolated human HSPCs. For this purpose, the isolated cells were pre expanded for 7 days in medium with $1 \%(\mathrm{v} / \mathrm{v})$ cytokine mix E. After pre expansion, approximately half of the cell population was positive for erythroid differentiation markers. The majority of this population consisted of $\mathrm{CD}_{7} 1^{+}$pro erythroblasts. The other half of the pre expanded cells was $\mathrm{CD} 71^{-} / \mathrm{CD} 235^{-}$represent ing uncommitted progenitors or cells undergoing nonerythroid differentiation (Figure S2). Pre expanded cells $\left(1.1 \times 10^{5}\right)$ were cultured for a further 14 days on the hydrogels with iron nanoparticles and without iron nanoparticles as control, yielding a total culture time of 21 days ( 7 days of pre expansion +14 days of differentiation on hydrogels; given days of analysis are always counted from the day of isolation, thus including also the 7 days of pre culture). During the differentiation on the hydrogels, the expansion medium was additionally supplemented with EPO alpha, mifepristone, human insulin, human apotransferrin, and poloxamer 188 to trigger erythropoiesis, ensuring the import of iron ions into the cells. The cells were analyzed after 14 and 21 days of culture in cell number, and the percentage of erythroid progenitor cells indicated by their expression of specific markers was measured. After 14 days of culture, no differences in the percentage of $\mathrm{CD} 1^{+} \mathrm{CD}_{235^{+}}$(more committed progenitors) or $\mathrm{CD} 235^{+}$ (late erythroid progenitors and/or mature erythrocytes) could be observed for cells cultured on flat hydrogel pads with or without iron nanoparticles. Only the percentage of $\mathrm{CD} 71^{+}$cells was significantly lower on the iron nanoparticle loaded gels than on the control gels. After a time period of 21 days, the cells on the iron nanoparticle composite hydrogels showed significantly higher percentages of more developed erythroid progenitor cells $\left(\mathrm{CD} 71^{+} \mathrm{CD} 235^{+}\right.$and $\mathrm{CD} 235^{+}$cells) compared to the flat hydrogel pads without iron nanoparticles (Figure 4). While the fluorescence intensity in the single positive populations $\left(\mathrm{CD}_{7} 1^{+}\right.$and $\left.\mathrm{CD} 235^{+}\right)$did not vary a lot over time, we see a decrease in the CD71 expression under both culture conditions in the double positive populations and an increase in the fluorescence intensity detected by CD235 
(a)
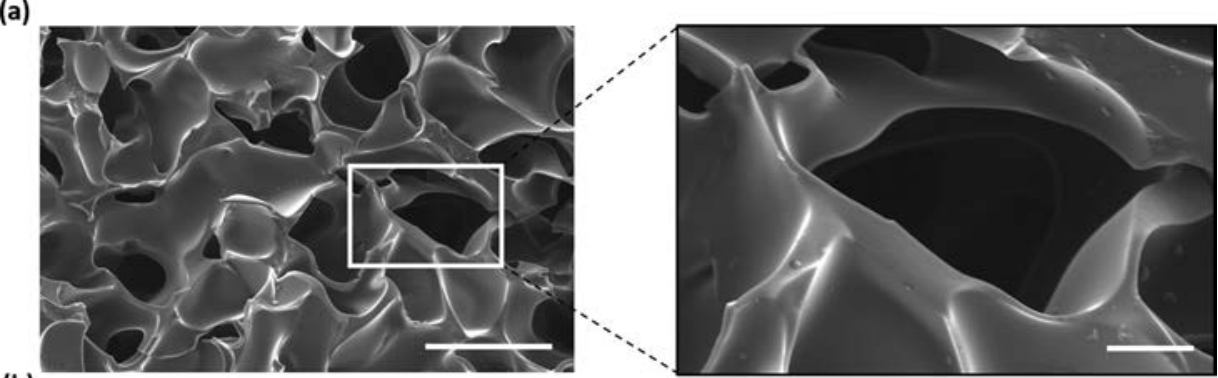

(b)

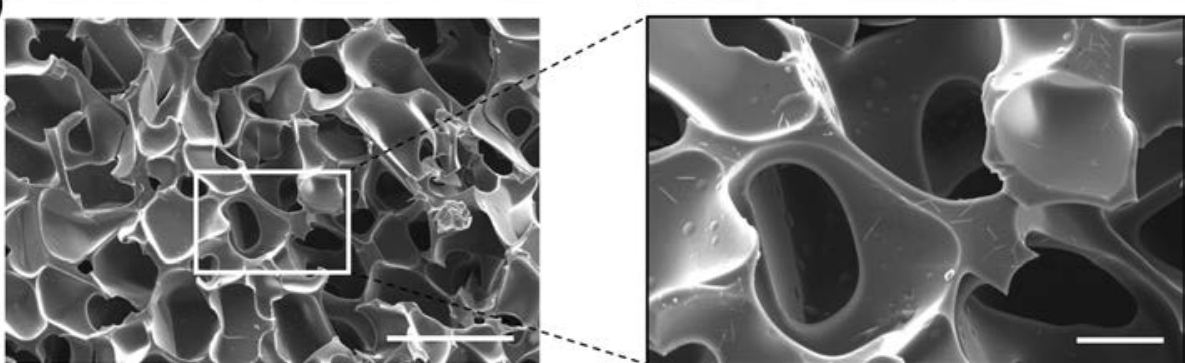

(c)

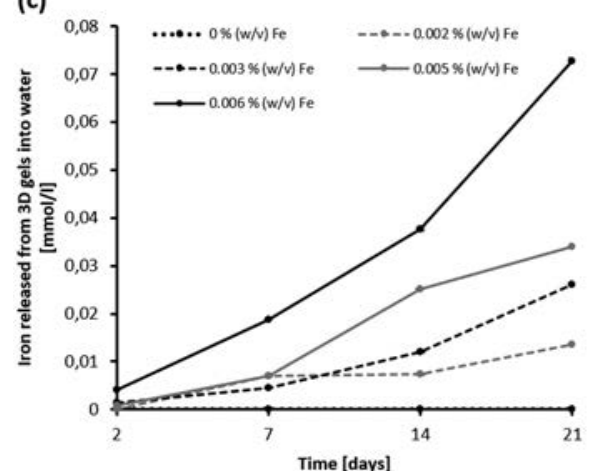

(d)

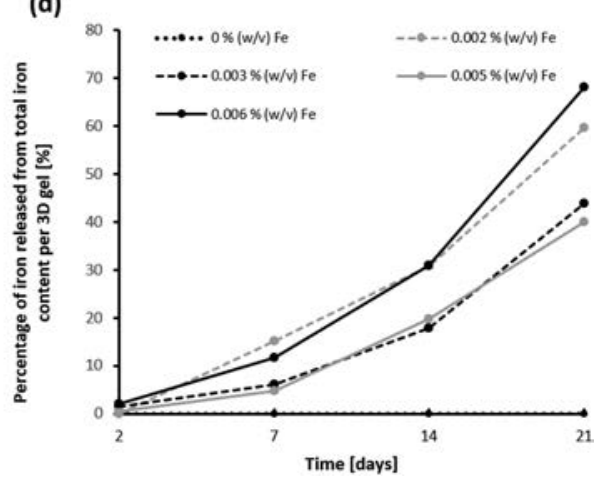

Figure 6. Iron content and release study of 3D iron nanoparticle scaffolds. (a) SEM pictures of a cross section of a 3D hydrogel scaffold showing the porous structure of the hydrogel. Scale bar: $100 \mu \mathrm{m}$ (left). The right picture represents a magnification of one pore. Scale bar: $20 \mu \mathrm{m}$. (b) SEM pictures of 3D hydrogels with $0.002 \%(\mathrm{w} / \mathrm{v}$ ) iron nanoparticles. Scale bar: $100 \mu \mathrm{m}$ (left). On the right side, a picture in higher magnification is shown. Scale bar: $20 \mu \mathrm{m}$. (c) Iron release after incubation of the 3D composite scaffolds with different concentrations of iron nanoparticles [0.002\% $(\mathrm{w} / \mathrm{v}), 0.003 \%(\mathrm{w} / \mathrm{v}), 0.005 \%(\mathrm{w} / \mathrm{v})$, and $0.006 \%(\mathrm{w} / \mathrm{v})]$ was measured over a period of 21 days $(\mathrm{SD} \leq 0.0006 \mathrm{mmol} / \mathrm{L})$ and $(\mathrm{d})$ release in percentage of the total iron mass embedded into the $3 \mathrm{D}$ scaffolds was calculated ( $\mathrm{SD} \leq 0.5 \%)$.

staining that was more pronounced on hydrogels releasing iron than on hydrogels without iron (Figure S3).

The absolute number of erythroid cells produced during the in vitro culture was calculated by multiplying the fractions of $\mathrm{CD} 71^{+}, \mathrm{CD} 71^{+} / \mathrm{CD} 235^{+}$, and $\mathrm{CD} 235^{+}$with the absolute cell numbers counted in the individual cultures on day 14 and day 21 (Figure 5). On day 14, the number of $\mathrm{CD} 71^{+} / \mathrm{CD} 235^{+}$ double positive cells was significantly different between hydrogels with and without iron nanoparticles. This effect substantiated during the following 7 days of culture. On day 21 significantly higher numbers of $\mathrm{CD} 71^{+} / \mathrm{CD} 235^{+}$erythroid progenitor cells could be isolated from the iron nanoparticle bearing hydrogels than from the ones without. Thus, it appears that iron ion release does not influence early erythroid differentiation, but supports differentiation and maturation of later erythroid progenitors, as it almost doubles the total yield of the $\mathrm{CD} 71^{+} / \mathrm{CD} 235^{+}$cells after 14 days and more than triples it after 21 days.

3D Hydrogels. To mimic the 3D environment in the red bone marrow, where erythropoiesis naturally occurs, the iron nanoparticle composite hydrogels were further developed to macroporous 3D scaffolds. These scaffolds were produced with different concentrations of iron nanoparticles [0.002-0.006\% $(\mathrm{w} / \mathrm{v})]$. The scanning electron microscopy (SEM) analysis of the developed macroporous hydrogel scaffolds demonstrated the porous structure (Figure $6 \mathrm{a}, \mathrm{b}$ ). The pore diameter was not affected by the presence of the nanoparticles in the hydrogel. With increasing concentrations of iron nanoparticles embed ded into the composite 3D scaffolds during production, the mass of iron measured by ICP OES in the ready gels increased accordingly to a maximum of $10.93 \mu \mathrm{g}$ per gel. For the 3D composite scaffolds with $0.002 \%(\mathrm{w} / \mathrm{v}), 0.003 \%(\mathrm{w} / \mathrm{v})$, and $0.005 \%(\mathrm{w} / \mathrm{v})$ iron nanoparticle loadings, iron contents of 2.628, 5.637, and $9.3245 \mu \mathrm{g} /$ gel were measured (Figure S4). Measurements of released iron revealed a constant increase of iron concentration in the water around the $3 \mathrm{D}$ composite scaffolds with all iron nanoparticle concentrations during 21 days of incubation (Figure 6c). The 3D scaffolds with the highest iron content $[0.006 \%(\mathrm{w} / \mathrm{v})$ iron nanoparticles $]$ released also the highest amount of iron ions into the supernatant after 7,14 , and 21 days $(0.019,0.038$, and 0.073 $\mathrm{mmol} / \mathrm{L}$ ) compared to the $3 \mathrm{D}$ composite scaffolds with a lower nanoparticle content. This corresponds to 1.05, 2.1, and $4.07 \mu \mathrm{g} / \mathrm{mL}$ iron, which is freely available for the cells in a culture. The second highest amount of iron was released from $0.005 \%(\mathrm{w} / \mathrm{v})$ iron nanoparticle composite gels with 0.025 
(a)

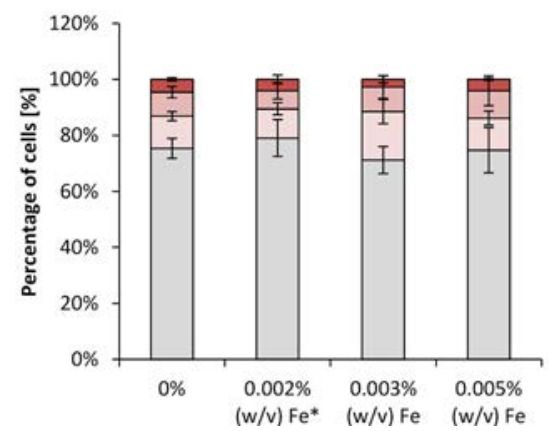

(b)

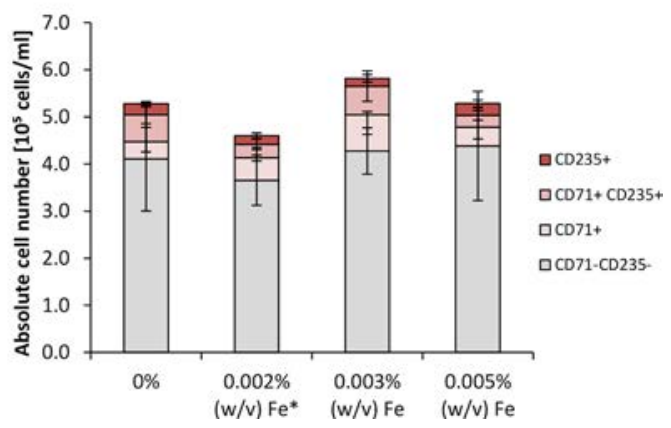

Figure 7. Percentage and absolute number of erythroid progenitors in $3 \mathrm{D}$ composite scaffolds with iron nanoparticles. The percentage (a) and the absolute number (b) of erythroid progenitor cells $\left(\mathrm{CD} 71^{+}, \mathrm{CD} 71^{+} / \mathrm{CD} 235^{+}\right.$, and $\left.\mathrm{CD} 235^{+}\right)$was analyzed after 21 days of culture in $3 \mathrm{D}$ hydrogels with $0.002 \%(\mathrm{w} / \mathrm{v}), 0.003 \%(\mathrm{w} / \mathrm{v})$, and $0.005 \%(\mathrm{w} / \mathrm{v})$ and without iron nanoparticles $(0 \%(\mathrm{w} / \mathrm{v})$ iron) in different concentrations. The error bars represent the SE. $* N=2$ independent experiments for $0.002 \%$ iron nanoparticles scaffolds, for all other conditions $N=3$ independent experiments.

$\mathrm{mmol} / \mathrm{L}(1.4 \mu \mathrm{g} / \mathrm{mL})$ after 14 days and $0.034 \mathrm{mmol} / \mathrm{L}(1.9$ $\mu \mathrm{g} / \mathrm{mL})$ after 21 days. Iron nanoparticle $3 \mathrm{D}$ composite scaffolds $[0.003 \%(\mathrm{w} / \mathrm{v})]$ released $0.012 \mathrm{mmol} / \mathrm{L}(0.67 \mu \mathrm{g} /$ $\mathrm{mL})$ and $0.026 \mathrm{mmol} / \mathrm{L}(1.46 \mu \mathrm{g} / \mathrm{mL})$ after 14 and 21 days, respectively. $3 \mathrm{D}$ scaffolds with the lowest iron nanoparticle loading revealed a released iron concentration of $0.014 \mathrm{mmol} /$ $\mathrm{L}(0.76 \mu \mathrm{g} / \mathrm{mL})$ in water after 21 days. Herein, it is important to note that with respect to the previously conducted iron release studies of flat hydrogel pads, the assumed amount of released iron into differentiation medium has to be considered 3 fold lower compared to the release into water (Figure 3).

The iron release in the percentage of the total iron mass within the 3D hydrogels increased during 21 days of incubation but did not seem to be dependent on the concentration of iron nanoparticles in the composite 3D scaffolds (Figure 6d). The scaffold with the highest iron concentration $[0.006 \%(\mathrm{w} / \mathrm{v})]$ released $68.1 \%$ of the incorporated iron after 21 days, followed by a total iron release of $59.6 \%$ of the scaffold with an iron content of $0.002 \%$ $(\mathrm{w} / \mathrm{v})$. Scaffolds provided with iron nanoparticles at a concentration of $0.005 \%(\mathrm{w} / \mathrm{v})$ and $0.003 \%(\mathrm{w} / \mathrm{v})$ released $43.7 \%$ and $40.0 \%$ of the incorporated iron into the supernatant. For the estimation of the iron release from 3D scaffolds with higher or lower iron nanoparticle loading, the iron content of the $3 \mathrm{D}$ composite scaffolds was plotted against the corresponding concentration found in the supernatant upon release from the $3 \mathrm{D}$ composite scaffolds after 21 days (Figure S5). Insertion of the iron content of the flat hydrogel pads $(4.17 \mu \mathrm{g}$ iron/gel) into the linear equation of the plotted graph revealed an iron release of $0.022 \mathrm{mmol} / \mathrm{L}$ after 21 days for a $3 \mathrm{D}$ hydrogel with the same iron content. Overall, the developed $3 \mathrm{D}$ composite scaffolds showed a porous architecture and were able to release iron with time.

The 3D hydrogels were seeded with HSPCs to analyze the impact of a constant iron release on the cells in a 3D environment. After 21 days of culture, no living cells could be isolated from the scaffolds with the highest iron nanoparticle content $(0.006 \%)$, while cell viability was ranging between 75 and $99 \%$ in scaffolds with lower iron content (Figure S6). From the scaffolds with lower iron nanoparticle loading, cells could be isolated and the percentage of $\mathrm{CD} 71^{+}, \mathrm{CD}_{7} 1^{+} /$ $\mathrm{CD}_{235^{+}}, \mathrm{CD} 235^{+}$, as well as $\mathrm{CD} 71^{-} / \mathrm{CD} 235^{-}$were measured using flow cytometry (Figure 7 ). In the percentage of early and late erythroid progenitors $\left(\mathrm{CD} 71^{+}, \mathrm{CD} 71^{+} / \mathrm{CD} 235^{+}\right.$, and $\mathrm{CD}_{235^{+}}$), no differences or a tendency between the used iron nanoparticle content were observed. Furthermore, we calculated the absolute number of erythroid progenitor cells, but no differences were revealed between the samples.

\section{DISCUSSION}

Finding new ways to produce erythrocytes by differentiation from HSPCs to a high extent is a necessary requirement to overcome donor limitations. To this end, culture systems are needed, which allow an investigation of the impact of different factors on the erythroid development of HSPCs. Iron is an important partner of the oxygen transporter hemoglobin in erythrocytes and it is involved in its synthesis. ${ }^{39,40}$ Extracellular iron is consumed by the cells in the transferrin bound form. The precursor apotransferrin binds iron resulting in the formation of transferrin, which can be transported into the cell and recycled for new iron transport. ${ }^{41}$ Because of the important role of iron in erythrocytes, the impact on proliferation or differentiation of precursor cells, and the fact that $\sim 80 \%$ of the iron in humans flows into the erythrocyte production, we were interested in the potential of iron to direct the in vitro differentiation of human HSPCs to erythrocytes. ${ }^{42}$ For this purpose, we developed an in vitro nanocomposite hydrogel system with a constant iron release, while apotransferrin was used as an additive during cell culture to ensure iron transfer into the cells.

For the development of an iron release system, we produced spherically shaped iron nanoparticles with an average size of $5.0 \mathrm{~nm}$ using the PLAL method in a PEG DA/MA solution. It is known that PLAL is a chemically clean method that yields composite materials in a one step synthesis, which is important for biological applications, as potential cross effects by toxic additives are avoided. ${ }^{23}$ During PLAL, polymer molecules can cause the size quenching effect, which results in a smaller iron particle size compared to when in water or acetone. ${ }^{43}$ The TEM images of the nanoparticles revealed that the surface coating with PEG chains sterically stabilizes the nanoparticles shown by a distinct interparticle distance, even though some agglomerates were observed. These iron nanoparticles were incorporated into PEG DA and PEG MA hydrogels with an even distribution, confirmed by $3 \mathrm{D}$ microscopy, and a mass load of $0.012 \%(\mathrm{w} / \mathrm{v})$. In order to provide an environment for the cells, which closely matches the architecture found in the bone marrow, we developed macroporous 3D PEG DA/PEG MA hydrogel scaffolds containing iron nanoparticles in varying amounts $[0.002-0.006 \%(\mathrm{w} / \mathrm{v})]$. The macroporous structure 
was intended to mimic trabecular bone regions, in which the red bone marrow-the place of natural erythropoiesis-is found. ${ }^{44,45}$ The aspired porous structure in the 3D scaffolds could be verified by SEM and revealed an architecture, which was also seen in the trabecular bone regions by other researchers. ${ }^{46,47}$ Both developed iron nanoparticle composite hydrogel systems (flat pads and 3D macroporous) showed a constant release of iron, to a certain extent, into the water and cell culture medium for 21 days. The iron ion release kinetics observed in this iron nanoparticle PEG nanocomposite significantly deviate from those previously reported in the literature for static release conditions. For hydrophobic silicon composites, release curves showed saturation for several different ion types for long release times and were reported to follow a two step mechanism first controlled by diffusion and at later stages by metal particle dissolution. ${ }^{48,49}$ However, particularly in hydrogel based release systems, for example, in the iron nanoparticle alginate system, the release process can be more complicated, as interactions between the gel matrix and the released ions could affect the gel matrix and thus influence ion release kinetics. ${ }^{50} \mathrm{~A}$ specific interaction between the released iron ions and a PEG matrix polymer, particularly in case the release is recorded in deionized water, is also conceivable. This is backed by the fact that PEG based polymers are frequently utilized in affinity partitioning of metal ions. Even though this process is mainly ruled by the attached chelating ligands, an ion adsorption by pure PEG is also reported. ${ }^{51}$ In another study, coating of dextran covered iron oxide nanoparticles with an additional layer of PEG significantly reduced the iron ion release, which seems to indicate ion scavenging by PEG. ${ }^{52}$

Based on these considerations, we propose the following hypothesis to explain the ion release properties in our PEGiron nanoparticle hydrogel system. Release experiments conducted in ionized water show a three times higher ion concentration in comparison to those conducted in cell culture medium. This is probably due to the fact that the cell culture medium already has a significant iron ion concentration, which slows down the release. A higher concentration gradient is achieved in water, which facilitates diffusion of iron irons. Furthermore, the release curves from the flat hydrogel pads as well as from the 3D gels exhibit counter intuitive shapes with sluggish release for 7 days and stronger release for longer times. This observation can be explained by the ion scavenging effect of the PEG chains in deionized water. This effect seems to be dominant for 7 days, while afterward the ion loading capacity of the matrix polymer is probably exceeded and much higher amounts of iron are released into the medium.

The total amount of iron released from the iron nanoparticle composite systems after 21 days into water was mostly in the range of, or lower than, the physiological iron content in human blood $(0.7-1.9 \mu \mathrm{g} / \mathrm{mL}) .{ }^{53}$ However, it has to be considered that the release into cell culture medium was approximately 3 times lower than in water. Much higher iron concentrations $(4.07 \mu \mathrm{g} / \mathrm{mL}$ or $0.073 \mathrm{mmol} / \mathrm{L})$ were found in the supernatants of the 3D composite scaffold with $0.006 \%$ $(\mathrm{w} / \mathrm{v})$ iron nanoparticles. In this context, it should be noted that the iron target contained $0.01 \%$ of unidentified contaminants ( $99.99 \%$ purity), however, the resulting release of potentially harmful trace metals was estimated to be negligible. As expected, the iron release from the flat composite hydrogels was lower than from the macroporous 3D scaffolds with similar iron content [flat hydrogels: $0.86 \mu \mathrm{g} / \mathrm{mL}$, macroporous 3D scaffolds with similar iron nanoparticle loading (estimated from the linear regression in Figure S5) $1.23 \mu \mathrm{g} / \mathrm{mL}$. This is probably attributed to the much higher specific surface area of the 3D gel from which iron could be released to the media. To the best of our knowledge, this is the first report of iron release systems for in vitro erythropoiesis.

We aimed to test two different approaches-a flat hydrogel release system and a macroporous $3 \mathrm{D}$ release system-to support in vitro erythropoiesis with iron releasing composite hydrogels, both having their advantages and disadvantages. While the macroporous 3D scaffolds are biomimetic and provide a more in vivo like environment for cells, they are relatively laborious in production and are more difficult to handle in cell culture. Particularly, the harvesting of cells for analysis or further application is more challenging. At the same time, the flat hydrogel pads are not biomimetic and provide a highly artificial environment to cells, however, they are straightforward in production, easy to handle in cell culture, and allow facile retrieval of cells.

Previous studies reported a supportive effect of biomimetic $3 \mathrm{D}$ scaffolds on in vitro red blood cell production. ${ }^{16,17}$ We took a similar biomimetic approach to provide the HSPCs a porous structure, as in the trabecular bone regions, and combined it with the iron release system. Both properties, the porous architecture as well as the iron release, were demonstrated. However, the iron releasing 3D scaffolds in the present study could not support in vitro erythropoiesis as reported in the above mentioned previous studies. After 21 days of culture, no differences in erythroid differentiation of the cells in the 3D scaffolds with or without iron nanoparticles could be observed. As mentioned above, the ratio between apotransferrin and iron and, hence, the resulting transferrin concentration affecting the erythropoiesis is important. ${ }^{22}$ Each apotransferrin has 2 iron binding sites, ${ }^{20}$ therefore, the $1.2 \mathrm{mg} / \mathrm{mL}(0.021 \mathrm{mmol} / \mathrm{L})$ apotransferrin added to the culture medium can theoretically bind to $1.63 \mu \mathrm{g} / \mathrm{mL}(0.029 \mathrm{mmol} / \mathrm{L})$ iron (with $M_{\text {apotransferrin }} \sim$ $81 \mathrm{kDa}$ and $\left.M_{\mathrm{Fe}} \sim 55 \mathrm{Da}\right)$. As the amount of iron released from the $3 \mathrm{D}$ composite scaffolds containing $0.003 \%(\mathrm{w} / \mathrm{v})$ or more iron nanoparticles into water is in this range or above it; we assume that the iron concentration released by the systems after 21 days might have been too high to be completely captured by apotransferrin to affect the erythropoiesis and the resulting iron overload inhibited the differentiation, as shown in previous studies by other researchers. ${ }^{21}$ Particularly, we assume that the local iron concentrations experienced by the cells within the macropores of the 3D scaffolds were relatively high, as within the pores, the ratio of the iron releasing hydrogel surface to the growth media containing pore volume is approximately 25 times higher than for the developed flat hydrogel pads, which release their iron to the bulk medium above the flat hydrogel. This assumption of locally high iron concentrations that might lead to cell death is supported by the findings of Lu et al., who showed that a high concentration of free iron induces cell death in hematopoietic cells. ${ }^{54}$ In line with this, we saw that at iron nanoparticle loading of $0.006 \%$ $(\mathrm{w} / \mathrm{v})$, in $3 \mathrm{D}$ hydrogels, no hematopoietic cells could be isolated from these gels upon culture, indicating that the cells died in this setting.

To assess whether the flat iron releasing composite hydrogels are an appropriate system to study the effect of continuously released iron ions on erythropoiesis, we seeded pre cultured HSPCs isolated from the human umbilical cord blood on the hydrogels with and without the iron nano 
particles. After 14 days of culture ( 7 days pre culture +7 days in differentiation medium on hydrogels), the results revealed significant differences in the percentage and absolute number of erythroid progenitor cells between the control and the iron releasing system. The iron release studies in medium lead to the assumption that the amount of iron released by the hydrogel was too small after 14 days to load the added $1.2 \mathrm{mg} /$ $\mathrm{mL}$ apotransferrin with iron, which can theoretically bind in total $\sim 1.63 \mu \mathrm{g} / \mathrm{mL}$ of iron to trigger the erythropoiesis of HSPCs. Previous studies showed that with an increase of iron saturated transferrin the consumption of iron by the cells increases, and the differentiation is triggered. ${ }^{22}$ In line with this, we found that when the iron release from the iron nanoparticle composite gels was increased after 21 days of culture by a factor of roughly 1.3 or 2.9 (in cell culture media or water, respectively) in comparison to day 14 , the percentage and total number of later erythroid progenitors was significantly increased on the iron releasing hydrogels, in comparison to the pristine hydrogels. However, it might also well be that the differentiation process had not proceeded far enough on day 14 to lead to larger amounts of cells in later differentiation stages, which were found to be influenced by the iron release by analysis on day 21 . This finding-that mainly later differentiation stages are affected by iron releaseis not surprising, as the hemoglobin synthesis starts in early basophilic erythroblasts, ${ }^{20}$ which are $\mathrm{CD} 71^{+} / \mathrm{CD} 235^{+}, 55,56$ and, thus, we expect these populations to be mainly susceptible to sufficient iron supply. Assuming the dependence of functional erythrocytes on the hemoglobin and iron supply, one could expect larger effects of iron ion release on erythroid differentiation. However, using hemoglobin knockout cells, Liu et al. could show that nucleated erythroid cell differ entiation is not dependent on the hemoglobin synthesis, (in contrast to reticulocyte survival and their terminal differ entiation to red blood cells). ${ }^{57}$ This finding explains why we could observe erythroid differentiation of HSPCs also in the absence of iron which is essential for hemoglobin synthesis.

In summary, with the developed iron nanoparticle hydrogel composite system, we could show for the first time the impact of constant iron ion release on in vitro erythroid differentiation of cord blood derived HSPCs. So far, other systems pursued approaches utilizing soluble factors as additives, which are often used in large amounts to increase the yield. However, most of these established procedures are conducted with similar additives and in a nonbiomimetic environment. ${ }^{10-13}$ To overcome the shortcomings of these procedures and to substantially increase the effectiveness of in vitro red blood cell production, new supplements and culture environments similar to the in vivo conditions will be needed. The present study is a first step toward this goal, by providing a system which meets these requirements and allows the establishment of iron release as an erythropoiesis supporting factor and analysis of its effects.

\section{CONCLUSIONS}

The presented flat iron nanoparticle composite hydrogels released an optimum of iron ions to trigger erythropoiesis, whereas the macroporous $3 \mathrm{D}$ scaffolds mimicking the porous structure of the bone marrow inhibited erythropoiesis most likely because of locally occurring high iron ion concentrations within the cell laden pores of the scaffold. Finding the optimal conditions for erythrocyte farming is a knife edge between triggering erythropoiesis to reach a high yield and preventing cell apoptosis. Our in vitro system allows fine tuning the concentration range on a small scale by varying the iron nanoparticle concentration in the hydrogels. This can help to build up new settings with iron nanoparticles as a new factor for erythrocyte production with the final goal of overcoming the issue of donor limitations.

\section{EXPERIMENTAL SECTION}

Iron Nanoparticle Embedding in Polymer Solutions by PLAL. For nanocomposite generation, nanoparticles were first embedded into a poly(ethylene glycol) methacrylate (PEG MA) poly(ethylene glycol) diacrylate (PEG DA) polymer mixture (PEG DA/MA) via PLAL. A picosecond ( $<10$ ps) Nd:YAG laser system (Atlantic, Ekspla, Vilnius, LT) at $1064 \mathrm{~nm}$ and a repetition rate of 100 $\mathrm{kHz}$ was used. The laser beam was focused by a $100 \mathrm{~mm}$ lens through a $3 \mathrm{~mm}$ liquid layer on the $99.99 \%$ pure iron bulk metal plate target (thickness $0.25 \mathrm{~mm}$, Sigma Aldrich, Saint Louis, USA), which was placed in a stirred batch chamber with a maximum volume of $30 \mathrm{~mL}$. The chamber was filled with a mixture of $2 \mathrm{~mL}$ of PEG MA $\left(M_{\mathrm{n}}=\right.$ $500 \mathrm{~g} / \mathrm{mol}$, Sigma Aldrich), $5 \mathrm{~mL}$ of PEG DA $\left(M_{\mathrm{n}}=700 \mathrm{~g} / \mathrm{mol}\right.$, Sigma Aldrich), and $15 \mathrm{~mL}$ of $\mathrm{ddH}_{2} \mathrm{O}$. The ablated mass of iron nanoparticles was determined by weighing the target before and after the ablation process on a balance [Precisa 300 9234/H PESA Waagen (Wetzikon, Switzerland)]. Furthermore, the iron nanoparticles in the mixed polymer solution, diluted with $\mathrm{dd}_{2} \mathrm{O}$, were analyzed by TEM (Zeiss EM 910, Carl Zeiss AG, Oberkochen, DE). To determine the number weighted particle size distributions, Feret diameters of 1000 iron nanoparticles were counted for the statistical analysis. The data were plotted into number weighted size histograms and fitted using a log normal function to obtain the average particle size of the fitted values. The polydispersity index (PDI) was calculated from the following equations ${ }^{35}$

$$
\begin{aligned}
& \operatorname{PDI}=\frac{\operatorname{Var}(x)}{x_{c}^{2}} \\
& \operatorname{Var}(x)=\mathrm{e}^{2 \ln \left(x_{c}\right)+w^{2}}\left(\mathrm{e}^{w^{2}}-1\right)
\end{aligned}
$$

where $x_{c}$ represents the particle average size and $w^{2}$ is the standard deviation.

Fabrication of Flat PEG-MA/PEG-DA Iron Nanoparticle Composite Hydrogel Pads. PEG DA700 $(1 \mathrm{~mL})$ was mixed with $1 \mathrm{~mL}$ of degassed water (10 min, ultrasonic bath). A total of $20 \mu \mathrm{L}$ of a 2 hydroxy 4' (2 hydroxyethoxy) 2 methylpropiophenone solution $(100 \mathrm{mg} / \mathrm{mL}$ in $70 \%(\mathrm{v} / \mathrm{v})$ ethanol (Sigma Aldrich)) was added as a photoinitiator and the mixture kept in darkness. A total of $450 \mu \mathrm{L}$ was used directly for the fabrication of the control gels without nanoparticles. For the fabrication of flat hydrogel pads with nanoparticles, $225 \mu \mathrm{L}$ of this solution was mixed with $225 \mu \mathrm{L}$ of the PEG DA/MA solution with ablated iron nanoparticles (0.012 wt $\%$; production procedure described above). The mixture $(450 \mu \mathrm{L})$ was pipetted immediately between two glass slides (quartz glass), separated by a $250 \mu \mathrm{m}$ spacer, and radiated with UV light for $30 \mathrm{~min}$. The formed hydrogels were removed from the glass plates and $16 \mathrm{~mm}$ circles punched out. The hydrogels were air dried for two weeks. The same procedure was performed with $450 \mu \mathrm{L}$ of the solution without nanoparticles for the fabrication of control hydrogels.

CLSM (Leica TCS SP8, Leica Microsystems, Wetzlar, DE) was used to visualize iron nanoparticles $(0.012 \mathrm{wt} \%)$ in the PEG DA/MA hydrogels and to qualitatively evaluate the distribution in a 3D matrix. The samples were irradiated at 470 and $532 \mathrm{~nm}$ (white light laser WLL2, $1.5 \mathrm{~mW}$ ), and the detection of luminescence signals was conducted between 472 and $528 \mathrm{~nm}$ and 533 and $590 \mathrm{~nm}^{23}$

Fabrication of 3D PEG-DA/MA Iron Nanoparticle Composite Hydrogels by Cryogelation. The colloid of laser generated iron nanoparticles in the polymer solution of PEG DA700 and PEG MA500 was also used for the preparation of the 3D hydrogel. $6.8 \%$ $(\mathrm{w} / \mathrm{v}), 13.6 \%(\mathrm{w} / \mathrm{v}), 20.4 \%(\mathrm{w} / \mathrm{v}), 27.2 \%(\mathrm{w} / \mathrm{v})$, and $34 \%(\mathrm{w} / \mathrm{v})$ of this solution was mixed with a PEG DA/MA mixture $(2 \mathrm{~mL}$ PEG

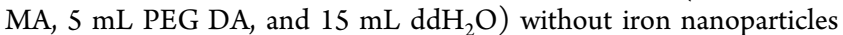
to an end volume of $1.73 \mathrm{~mL}$. A $1.5 \mathrm{M} \mathrm{NaCl}$ solution $(500 \mu \mathrm{L})$ and 
$2.77 \mathrm{~mL}$ of $\mathrm{ddH}_{2} \mathrm{O}$ were added to these mixtures. For the polymerization of the $\mathrm{NaCl}$-iron nanoparticle-PEG solution, 250 $\mu \mathrm{L} 10 \%(\mathrm{w} / \mathrm{v})$ ammonium persulfate and $3.75 \mu \mathrm{L}$ tetramethylethy lenediamine were added and the mixture was transferred into a cylindrical vessel with $1 \mathrm{~cm}$ in diameter that was precooled at $-20{ }^{\circ} \mathrm{C}$ for $1 \mathrm{~h}$. Afterward, the solution was frozen at $-20^{\circ} \mathrm{C}$ for $24 \mathrm{~h}$. During this cryogelation process, the pores were formed in the hydrogel. After $24 \mathrm{~h}$, the bulk hydrogel was thawed and cut into $4 \mathrm{~mm}$ thick pieces. The hydrogels were washed 6 times in $50 \mathrm{~mL}$ of $\mathrm{ddH}_{2} \mathrm{O}$ for $20 \mathrm{~min}$ each and freeze dried (Alphal 4, Martin Christ Gefriertrocknungsan lagen, Osterode am Harz, Germany), after dehydration in an increasing ethanol series [50\% (v/v), 60\% (v/v), 70\% (v/v), 80\% $(\mathrm{v} / \mathrm{v}), 90 \%(\mathrm{v} / \mathrm{v})$, and two times in $100 \%(\mathrm{v} / \mathrm{v})$; each step carried out for $10 \mathrm{~min}]$.

Iron Release Studies from Iron Nanoparticle Composite Hydrogels in Water and Media. The time series analysis was performed with both types of hydrogel in water and in Hematopoietic Progenitor Cell Expansion Medium DXF (PromoCell, Heidelberg, Germany) supplemented with a $1 \%(\mathrm{v} / \mathrm{v})$ penicillin/streptomycin solution (Sigma Aldrich) and 1\% (v/v) Cytokine Mix E (PromoCell). For this purpose, the gels (two gels per time point) were put into 24 well plates (Greiner Bio One, Frickenhausen, Germany) completely immersed in $2.2 \mathrm{~mL}$ of $\mathrm{ddH}_{2} \mathrm{O}$ or media and incubated for 21 days at $37{ }^{\circ} \mathrm{C}, 5 \% \mathrm{CO}_{2}$. The supernatant $(1 \mathrm{~mL})$ was taken from the sample preparation for the respective time point after $1,7,14$, and 21 days, and the iron content in the supernatant was analyzed via inductively coupled plasma optical emission spectrometry (ICP OES) using an optical emission spectrometer Optima 8300DV (PerkinElmer, Waltham, Massachusetts, USA). For this purpose, $1 \mathrm{~mL}$ of the supernatant was mixed with $1.5 \mathrm{~mL} \mathrm{HNO}_{3}, 0.3 \mathrm{~mL} \mathrm{H}_{2} \mathrm{O}_{2}$, and $0.2 \mathrm{~mL}$ of $\mathrm{H}_{2} \mathrm{SO}_{4}$ and afterward incubated at $80{ }^{\circ} \mathrm{C}$ until the sample was evaporated. The evaporated samples were dissolved in highly purified $\mathrm{H}_{2} \mathrm{O}$ and the iron content was measured via ICP OES. Standard addition was performed with iron concentrations of 10 and $100 \mathrm{mg} / \mathrm{L}$ solubilized in $1 \mathrm{~mL}$ culture media with a maximal concentration of $1 \%$ (v/v) [Iron, plasma standard solution, Specpure, Fe $1000 \mu \mathrm{g} / \mathrm{mL}$ ( $\mathrm{Fe}\left(\mathrm{NO}_{3}\right)_{3} \cdot 9 \mathrm{H}_{2} \mathrm{O}$ in $5 \% \mathrm{HNO}_{3}$ ] (Alfa Aesar, Kandel, Germany).

Iron Content Study of Fabricated Hydrogels. One batch of fabricated flat hydrogel pads and one batch of $3 \mathrm{D}$ hydrogels were dehydrated in an increasing ethanol series $[50 \%(\mathrm{v} / \mathrm{v}), 60 \%(\mathrm{v} / \mathrm{v})$, $70 \%(\mathrm{v} / \mathrm{v}), 80 \%(\mathrm{v} / \mathrm{v}), 90 \%(\mathrm{v} / \mathrm{v})$, and twice in $100 \%(\mathrm{v} / \mathrm{v})]$ for 10 min each. Afterward, the samples were frozen at $-80{ }^{\circ} \mathrm{C}$ for $24 \mathrm{~h}$ in $100 \%(\mathrm{v} / \mathrm{v})$ ethanol and freeze dried. The lyophilized hydrogels were analyzed by ICP OES.

SEM of 3D Hydrogels with and without Iron Nanoparticles. The 3D hydrogels were dehydrated and frozen at $-80{ }^{\circ} \mathrm{C}$ in $100 \%$ (v/ $\mathrm{v}$ ) ethanol as described above. Afterward, the hydrogels were freeze dried for $24 \mathrm{~h}$ and coated with a $5 \mathrm{~nm} 80 \%$ gold $/ 20 \%$ platinum layer by using a MED020 Coating System (Bal Tec, Balzers, Liechten stein). Scanning electron micrographs were obtained, using a Philips XL 30 FEG ESEM (ThermoFisher Scientific, Electron Microscopy Solutions, Hillsboro, Orgegon, USA) and operated at an acceleration voltage of $10 \mathrm{kV}$ at high vacuum or $20 \mathrm{kV}$ at a chamber pressure of $133 \mathrm{~Pa}$ (1 Torr).

Isolation of $\mathrm{CD}^{+} 4^{+}$HSPCs from Umbilical Cord Blood. Umbilical cord blood samples were obtained from DKMS (Deutsche Knochenmarkspenderdatei), Dresden, Germany, and from DRK (Deutsches Rotes Kreuz) blood donation service, Mannheim, Germany, with approval by the local ethics committee (Ethik Kommission bei der Landesärztekammer Baden Württemberg, Germany, B F 2013 111) and informed consent of the parents. CD34 positive $\left(\mathrm{CD} 34^{+}\right)$HSPCs were isolated from the umbilical cord blood with magnetic microbeads labeled with anti CD34 antibodies (Miltenyi Biotec, Bergisch Gladbach, Germany) according to manufacturer's instructions.

Preculture/expansion of $\mathrm{CD}^{+} 4^{+}$HSPCs for Subsequent Erythroid Differentiation. CD $34^{+}$cells $\left(1.3 \times 10^{5}\right.$ cells $\left./ \mathrm{mL}\right)$ were cultured in $2.2 \mathrm{~mL}$ of Hematopoietic Progenitor Cell Expansion Medium DXF (Promocell) supplemented with a 1\% (v/v) penicillin/ streptomycin solution (Sigma Aldrich) and 1\% (v/v) Cytokine Mix E (Promocell) for $7 \mathrm{~d}$.

Erythroid Differentiation of $\mathrm{CD}_{3} 4^{+}$Cells on Flat Hydrogel Pads. The flat hydrogel pads with or without iron nanoparticles were sterilized by UV radiation for $25 \mathrm{~min}$ on both sides, placed in 24 well plates and washed with Hematopoietic Progenitor Cell Expansion Medium DXF without supplements. After equilibration for $10 \mathrm{~min}$ in the medium, the hydrogels were washed again in the same media. Finally, $2.2 \mathrm{~mL}$ of modified media with supplements were pipetted into the wells and $1.1 \times 10^{5}$ of the pre cultured $\mathrm{CD} 34^{+}$cells were seeded directly onto the hydrogels. The modified Hematopoietic Progenitor Cell Expansion Medium DXF contained the following supplements: $1 \%(\mathrm{v} / \mathrm{v})$ penicillin/streptomycin, $1 \%(\mathrm{v} / \mathrm{v})$ Cytokine Mix E, $4 \mathrm{U} / \mathrm{mL}$ EPO alpha (PromoCell), $3 \mu \mathrm{M}$ Mifepristone (Sigma Aldrich), $10 \mu \mathrm{g} / \mathrm{mL}$ of human Insulin (PromoCell), $1.2 \mathrm{mg} / \mathrm{mL}$ of human Apotransferrin (PromoCell), and 0.05\% (v/v) Poloxamer 188 (Sigma Aldrich). The cells were cultured for further $14 \mathrm{~d}$ in the differentiation media at $37{ }^{\circ} \mathrm{C}$ and $5 \% \mathrm{CO}_{2}$ without media change. Thus, the cells were cultured for a total of 21 days ( 7 days pre expansion without hydrogels +14 days differentiation on hydrogels). Time points of the analysis were counted from the day of isolation as day 0 . The same number of cells was seeded into a well of a tissue culture plate as a control. The total number of cells was counted on day 14 and 21 with a Neubauer chamber (VWR International, Radnor, USA) after staining with $0.4 \%$ (v/v) trypan blue (Sigma Aldrich) and the percentage of erythroid progenitor cells was determined by flow cytometry.

Erythroid Differentiation of CD34+ Cells in 3D Hydrogels. The freeze dried 3D hydrogels were sterilized by UV radiation for 25 min on both sides and placed in 24 well plates. $5 \times 10^{5}$ of the pre cultured $\mathrm{CD}_{3} 4^{+}$cells were seeded onto the hydrogels and afterward the hydrogels were placed in $2.2 \mathrm{~mL}$ modified media with supplements $[1 \%(\mathrm{v} / \mathrm{v})$ penicillin/streptomycin solution, $1 \%(\mathrm{v} / \mathrm{v})$ Cytokine Mix E, $4 \mathrm{U} / \mathrm{mL}$ EPO alpha, $3 \mu \mathrm{M}$ Mifepristone, $10 \mu \mathrm{g} / \mathrm{mL}$ human insulin, $1.2 \mathrm{mg} / \mathrm{mL}$ human apotransferrin, $0.05 \%(\mathrm{v} / \mathrm{v})$ Poloxamer 188]. The cells were cultured at $37{ }^{\circ} \mathrm{C}$ and $5 \% \mathrm{CO}_{2}$. At day 21 , the cells were analyzed by flow cytometry.

Flow Cytometric Analysis. After isolation of the $\mathrm{CD} 34^{+}$cells from the blood samples, the purity of the CD $34^{+}$HSPCs was checked with flow cytometry using anti CD34 PE antibodies (Invitrogen, Carlsbad, USA) and the respective isotype control (Invitrogen, Carlsbad, USA). For all experiments, a minimum purity of $98 \%$ $\mathrm{CD}_{3} 4^{+}$cells was ensured. On day 14 and 21 of culture, the cells were immunostained with anti glycophorin A (anti CD235a PE) and anti transferrin receptor (CD71 vioblue) antibodies (both Miltenyi Biotec) and their respective isotype controls (Miltenyi Biotec). For immunostaining, a minimum of 20,000 cells (up to 100,000 , if available) were washed with Dulbecco's phosphate buffered saline (Sigma Aldrich) containing the fetal bovine serum (0.1\% (v/v), Sigma Aldrich) and resuspended in $50 \mu \mathrm{L}$ of the same buffer. Cells were stained with $5 \mu \mathrm{L}$ of antibodies and an appropriate isotype control for $10 \mathrm{~min}$ at $4{ }^{\circ} \mathrm{C}$, in the dark. Flow cytometry was performed using an Attune Acoustic Focusing Cytometer (Life technologies, Darmstadt, Germany) or MACSQuant Analyzer 10 (Miltenyi Biotec) and the data were analyzed with FlowJo V10.0.7 (Tree Star Inc., Ashland, Oregon, USA).

Iron Spiked Cell Culture. For an estimation of iron related effects on erythroid differentiation, freshly isolated $\mathrm{CD} 34^{+}$cells were first expanded and then differentiated in Hematopoietic Progenitor Cell Expansion Medium DXF (Promocell) without iron, or spiked with $0.008,0.0125$, and $0.017 \mathrm{mg} / \mathrm{L}$ of the $\mathrm{Fe}\left(\mathrm{NO}_{3}\right)_{3} \cdot 9 \mathrm{H}_{2} \mathrm{O}$ solution (Alfa Aesar, Kandel, Germany) and cultivated for 21 days as described before. At day 7, 14 and 21 of differentiation cell populations were assessed via the flow cytometry analysis with anti glycophorin A (anti CD235a PE) and anti transferrin receptor (CD71 vioblue) antibodies and their respective isotype controls (Miltenyi Biotec) as outlined above.

Data Analysis and Statistics. For data analysis and graphical representation, software MS Excel (Microsoft, Redmond, Wash ington, USA) was used. In experiments with $N \leq 3$, the standard error 
(SE) was calculated. To test for statistically significant differences due to iron release, paired, one sided t tests were carried out, as it was expected that iron acts only in one direction on differentiation because of the dependence of erythroid maturation on hemoglobin, and thus iron supply.

\section{AUTHOR INFORMATION}

\section{Corresponding Author}

Cornelia Lee Thedieck - Institute of Cell Biology and Biophysics, Leibniz University Hannover, Hannover 30419, Germany; ; Phone: +49 511762 5629; Email: lee thedieck@cell.uni hannover.de; Fax: +49511762 2606

\section{Authors}

Katharina Brändle - Institute of Functional Interfaces, Karlsruhe Institute of Technology (KIT), Eggenstein Leopoldshafen 76344, Germany; Institute of Cell Biology and Biophysics, Leibniz University Hannover, Hannover 30419, Germany

Timna C. Bergmann - Institute of Cell Biology and Biophysics, Leibniz University Hannover, Hannover 30419, Germany

Annamarija Raic - Institute of Functional Interfaces, Karlsruhe Institute of Technology (KIT), Eggenstein Leopoldshafen 76344, Germany; Institute of Cell Biology and Biophysics, Leibniz University Hannover, Hannover 30419, Germany

Yaya Li - Technical Chemistry I and Center for Nanointegration Duisburg Essen (CENIDE), University of Duisburg Essen, Essen 45141, Germany

Nina Million - Technical Chemistry I and Center for Nanointegration Duisburg Essen (CENIDE), University of Duisburg Essen, Essen 45141, Germany

Christoph Rehbock - Technical Chemistry I and Center for Nanointegration Duisburg Essen (CENIDE), University of Duisburg Essen, Essen 45141, Germany;

Stephan Barcikowski - Technical Chemistry I and Center for Nanointegration Duisburg Essen (CENIDE), University of Duisburg Essen, Essen 45141, Germany;

\section{Author Contributions}

K.B. and T.C.B. contributed equally. The manuscript was written through contributions of all authors. All authors have given approval to the final version of the manuscript.

\section{Notes}

The authors declare no competing financial interest.

\section{ACKNOWLEDGMENTS}

We thank Marita Heinle (Karlsruhe Institute of Technology) for ICP OES measurements and Chandralekha Chatterjee (Leibniz University Hannover) for proof reading the manu script. The project was supported by the BMBF Nano MatFutur Program (FKZ 13N12968 and 13XP5076A). This project has received funding from the European Research Council (ERC) under the European Union's Horizon 2020 research and innovation programme (grant agreement no. 757490). C.L.T. acknowledges support from the framework of the SMART BIOTECS alliance between the Technische Universität Braunschweig and the Leibniz Universität Hann over. This initiative is supported by the Ministry of Science and Culture (MWK) of Lower Saxony, Germany. Further thanks goes to the "Deutsche Forschungsgemeinschaft (DFG) for funding within the priority program SPP 1327. Y.L. acknowledges the Chinese Research Council for financial support.

\section{ABBREVIATIONS}

CLSM, confocal laser scanning microscopy; HSPC, hema topoietic stem and progenitor cell; ICP OES, inductively coupled plasma optical emission spectrometry; PEG DA, poly (ethylene glycol) diacrylate; PEG MA, poly(ethylene glycol) methacrylate; PLAL, pulsed laser ablation in liquids; SEM, scanning electron microscopy; TPU, thermoplastic polyur ethane; TEM, transmission electron microscopy

\section{REFERENCES}

(1) Douay, L. Why industrial production of red blood cells from stem cells is essential for tomorrow's blood transfusion. Regen. Med. 2018, 13, 627-632.

(2) Li, X.; Wu, Z.; Fu, X.; Han, W. How Far Are Stem Cell Derived Erythrocytes from the Clinical Arena? BioScience 2013, 63, 632-643.

(3) Timmins, N. E.; Nielsen, L. K. Blood cell manufacture: current methods and future challenges. Trends Biotechnol. 2009, 27, 415-422.

(4) Migliaccio, A. R.; Whitsett, C.; Papayannopoulou, T.; Sadelain, $\mathrm{M}$. The potential of stem cells as an in vitro source of red blood cells for transfusion. Cell Stem Cell 2012, 10, 115-119.

(5) Dellinger, E. P.; Anaya, D. A. Infectious and immunologic consequences of blood transfusion. Crit. Care 2004, 8, S18-S23.

(6) García Roa, M.; Del Carmen Vicente Ayuso, M.; Bobes, A. M.; Pedraza, A. C.; González Fernández, A.; Martín, M. P.; Sáez, I.; Seghatchian, J.; Gutiérrez, L. Red blood cell storage time and transfusion: current practice, concerns and future perspectives. Blood Transfus. 2017, 15, 222-231.

(7) Neildez Nguyen, T. M. A.; Wajcman, H.; Marden, M. C.; Bensidhoum, M.; Moncollin, V.; Giarratana, M. C.; Kobari, L.; Thierry, D.; Douay, L. Human erythroid cells produced ex vivo at large scale differentiate into red blood cells in vivo. Nat. Biotechnol. 2002, 20, 467-472.

(8) Seita, J.; Weissman, I. L. Hematopoietic stem cell: self renewal versus differentiation. Wiley Interdiscip. Rev.: Syst. Biol. Med. 2010, 2, 640-653.

(9) Merryweather Clarke, A. T.; Atzberger, A.; Soneji, S.; Gray, N.; Clark, K.; Waugh, C.; McGowan, S. J.; Taylor, S.; Nandi, A. K.; Wood, W. G.; Roberts, D. J.; Higgs, D. R.; Buckle, V. J.; Robson, K. J. $\mathrm{H}$. Global gene expression analysis of human erythroid progenitors. Blood 2011, 117, e96-e108.

(10) Huang, X.; Shah, S.; Wang, J.; Ye, Z.; Dowey, S. N.; Tsang, K. M.; Mendelsohn, L. G.; Kato, G. J.; Kickler, T. S.; Cheng, L. Extensive ex vivo expansion of functional human erythroid precursors 
established from umbilical cord blood cells by defined factors. Mol. Ther. 2014, 22, 451-463.

(11) Rallapalli, S.; Guhathakurta, S.; Narayan, S.; Bishi, D. K.; Balasubramanian, V.; Korrapati, P. S. Generation of clinical grade red blood cells from human umbilical cord blood mononuclear cells. Cell Tissue Res. 2019, 375, 437-449.

(12) Zhang, Y.; Wang, C.; Wang, L.; Shen, B.; Guan, X.; Tian, J.; Ren, Z.; Ding, X.; Ma, Y.; Dai, W.; Jiang, Y. Large Scale Ex Vivo Generation of Human Red Blood Cells from Cord Blood CD34+ Cells. Stem Cells Transl. Med. 2017, 6, 1698-1709.

(13) Caminal, M.; Labrozzi, J. P.; Oliver Vila, I.; Alzaga Gragera, M.; Marín Gallén, S.; Pla, A.; García, J.; Vives, J. Ex vivo production of red blood cells from human cord blood. BMC Proc. 2015, 9, P67.

(14) Bayley, R.; Ahmed, F.; Glen, K.; McCall, M.; Stacey, A.; Thomas, R. The productivity limit of manufacturing blood cell therapy in scalable stirred bioreactors. J. Tissue Eng. Regener. Med. 2018, 12, e368-e378.

(15) Raic, A.; Rödling, L.; Kalbacher, H.; Lee Thedieck, C. Biomimetic macroporous PEG hydrogels as 3D scaffolds for the multiplication of human hematopoietic stem and progenitor cells. Biomaterials 2014, 35, 929-940.

(16) Lee, E.; Han, S. Y.; Choi, H. S.; Chun, B.; Hwang, B.; Baek, E. J. Red blood cell generation by three dimensional aggregate cultivation of late erythroblasts. Tissue Eng., Part A 2015, 21, 817-828.

(17) Severn, C. E.; Macedo, H.; Eagle, M. J.; Rooney, P.; Mantalaris, A.; Toye, A. M. Polyurethane scaffolds seeded with CD34(+) cells maintain early stem cells whilst also facilitating prolonged egress of haematopoietic progenitors. Sci Rep. 2016, 6, 32149.

(18) Severn, C. E.; Eissa, A. M.; Langford, C. R.; Parker, A.; Walker, M.; Dobbe, J. G. G.; Streekstra, G. J.; Cameron, N. R.; Toye, A. M. Ex vivo culture of adult CD34+ stem cells using functional highly porous polymer scaffolds to establish biomimicry of the bone marrow niche. Biomaterials 2019, 225, 119533.

(19) Bouchnita, A.; Rocca, A.; Fanchon, E.; Koury, M. J.; Moulis, J. M.; Volpert, V. Multi scale Modelling of Erythropoiesis and Hemoglobin Production. J. Inorg. Organomet. Polym. 2016, 26, $1362-1379$.

(20) Ferreira, G. C.; Kadish, K. M.; Smith, K. M.; Guilard, R. Handbook of Porphyrin Science: With Applications to Chemistry, Physics, Materials Science, Engineering, Biology and Medicine; World Scientific Publishing Company: Singapore, 2013; Vol. 26-30.

(21) Taoka, K.; Kumano, K.; Nakamura, F.; Hosoi, M.; Goyama, S.; Imai, Y.; Hangaishi, A.; Kurokawa, M. The effect of iron overload and chelation on erythroid differentiation. Int. J. Hematol. 2012, 95, 149159.

(22) Byrnes, C.; Lee, Y. T.; Meier, E. R.; Rabel, A.; Sacks, D. B.; Miller, J. L. Iron dose dependent differentiation and enucleation of human erythroblasts in serum free medium. J. Tissue Eng. Regener. Med. 2016, 10, E84-E89.

(23) Blaeser, A.; Million, N.; Campos, D. F. D.; Gamrad, L.; Köpf, M.; Rehbock, C.; Nachev, M.; Sures, B.; Barcikowski, S.; Fischer, H. Laser based in situ embedding of metal nanoparticles into bioextruded alginate hydrogel tubes enhances human endothelial cell adhesion. Nano Res. 2016, 9, 3407-3427.

(24) Sadeghi, L.; Tanwir, F.; Yousefi Babadi, V. In vitro toxicity of iron oxide nanoparticle: oxidative damages on Hep G2 cells. Exp. Toxicol. Pathol. 2015, 67, 197-203.

(25) Zhang, D.; Gökce, B. Perspective of laser prototyping nanoparticle polymer composites. Appl. Surf. Sci. 2017, 392, 9911003.

(26) Maurer, E.; Barcikowski, S.; Gökce, B. Process Chain for the Fabrication of Nanoparticle Polymer Composites by Laser Ablation Synthesis. Chem. Eng. Technol. 2017, 40, 1535-1543.

(27) Amendola, V.; Meneghetti, M. What controls the composition and the structure of nanomaterials generated by laser ablation in liquid solution? Phys. Chem. Chem. Phys. 2013, 15, 3027-3046.

(28) Zhang, D.; Gökce, B.; Barcikowski, S. Laser Synthesis and Processing of Colloids: Fundamentals and Applications. Chem. Rev. 2017, 117, 3990-4103.
(29) Million, N.; Coger, V.; Wilke, P.; Rehbock, C.; Vogt, P. M.; Pich, A.; Barcikowski, S. Water based, surfactant free cytocompatible nanoparticle microgel composite biomaterials - rational design by laser synthesis, processing into fiber pads and impact on cell proliferation. BioNanoMaterials 2017, 18, 20170004.

(30) Wagener, P.; Brandes, G.; Schwenke, A.; Barcikowski, S. Impact of in situ polymer coating on particle dispersion into solid laser generated nanocomposites. Phys. Chem. Chem. Phys. 2011, 13, 51205126.

(31) Optically Induced Nanostructures: Biomedical and Technical Applications; Ostendorf, A., König, K., Eds.; De Gruyter: Berlin/ Boston, 2015

(32) Sowa Söhle, E. N.; Schwenke, A.; Wagener, P.; Weiss, A.; Wiegel, H.; Sajti, C. L.; Haverich, A.; Barcikowski, S.; Loos, A. Antimicrobial efficacy, cytotoxicity, and ion release of mixed metal $(\mathrm{Ag}, \mathrm{Cu}, \mathrm{Zn}, \mathrm{Mg}$ ) nanoparticle polymer composite implant material. BioNanoMaterials 2013, 14, 217-227.

(33) Streubel, R.; Barcikowski, S.; Gökce, B. Continuous multigram nanoparticle synthesis by high power, high repetition rate ultrafast laser ablation in liquids. Opt. Lett. 2016, 41, 1486-1489.

(34) Hess, C.; Schwenke, A.; Wagener, P.; Franzka, S.; Laszlo Sajti, C.; Pflaum, M.; Wiegmann, B.; Haverich, A.; Barcikowski, S. Dose dependent surface endothelialization and biocompatibility of polyur ethane noble metal nanocomposites. J. Biomed. Mater. Res., Part A 2014, 102, 1909-1920.

(35) Streich, C. Laser synthesized Bioconjugated Noble Metal Nanoparticles-Rational Design and Efficacy against Pathological Protein Aggregation. Ph.D. Dissertation, DuEPublico, 2017.

(36) Bapat, A.; Perrey, C. R.; Campbell, S. A.; Barry Carter, C.; Kortshagen, U. Synthesis of highly oriented, single crystal silicon nanoparticles in a low pressure, inductively coupled plasma. J. Appl. Phys. 2003, 94, 1969-1974.

(37) Malm, J. O.; O’Keefe, M. A. Deceptive "lattice spacings" in high resolution micrographs of metal nanoparticles. Ultramicroscopy 1997, 68, 13-23.

(38) Klein, S.; Petersen, S.; Taylor, U.; Rath, D.; Barcikowski, S. Quantitative visualization of colloidal and intracellular gold nano particles by confocal microscopy. J. Biomed. Optic. 2010, 15, 036015.

(39) Vaisman, B.; Fibach, E.; Konijn, A. M. Utilization of intracellular ferritin iron for hemoglobin synthesis in developing human erythroid precursors. Blood 1997, 90, 831-838.

(40) Garnica, A. D. Trace metals and hemoglobin metabolism. Ann. Clin. Lab. Sci. 1981, 11, 220-228.

(41) Luck, A. N.; Mason, A. B. Transferrin mediated cellular iron delivery. Curr. Top. Membr. 2012, 69, 3-35.

(42) Khalil, S.; Delehanty, L.; Grado, S.; Holy, M.; White, Z.; Freeman, K.; Kurita, R.; Nakamura, Y.; Bullock, G.; Goldfarb, A. Iron modulation of erythropoiesis is associated with Scribble mediated control of the erythropoietin receptor. J. Exp. Med. 2018, 215, 661679.

(43) de Bonis, A.; Lovaglio, T.; Galasso, A.; Santagata, A.; Teghil, R. Iron and iron oxide nanoparticles obtained by ultra short laser ablation in liquid. Appl. Surf. Sci. 2015, 353, 433-438.

(44) Takaku, T.; Malide, D.; Chen, J.; Calado, R. T.; Kajigaya, S.; Young, N. S. Hematopoiesis in 3 dimensions: human and murine bone marrow architecture visualized by confocal microscopy. Blood 2010, 116, e41-e55.

(45) Walkley, C. R. Erythropoiesis, anemia and the bone marrow microenvironment. Int. J. Hematol. 2011, 93, 10-13.

(46) Crane, G. M.; Jeffery, E.; Morrison, S. J. Adult haematopoietic stem cell niches. Nat. Rev. Immunol. 2017, 17, 573-590.

(47) von Meyer, G. H. The classic: The architecture of the trabecular bone (tenth contribution on the mechanics of the human skeletal framework). Clin. Orthop. Relat. Res. 2011, 469, 3079-3084.

(48) Hahn, A.; Brandes, G.; Wagener, P.; Barcikowski, S. Metal ion release kinetics from nanoparticle silicone composites. J. Controlled Release 2011, 154, 164-170.

(49) Hahn, A.; Günther, S.; Wagener, P.; Barcikowski, S. Electrochemistry controlled metal ion release from silicone elastomer 
nanocomposites through combination of different metal nano particles. J. Mater. Chem. 2011, 21, 10287.

(50) Li, Y.; Rehbock, C.; Nachev, M.; Stamm, J.; Sures, B.; Blaeser, A.; Barcikowski, S. Matrix specific mechanism of Fe ion release from laser generated 3D printable nanoparticle polymer composites and their protein adsorption properties. Nanotechnology 2020, DOI: $10.1088 / 13616528 / a b 94 d a$, [Online early access].

(51) Aguiñaga DÍAz, P. A.; Guzman, R. Z. Affinity Partitioning of Metal Ions in Aqueous Polyethylene Glycol/Salt Two Phase Systems with PEG Modified Chelators. Sep. Sci. Technol. 1996, 31, 14831499 .

(52) Mohammadi, M. R.; Malkovskiy, A. V.; Jothimuthu, P.; Kim K. M.; Parekh, M.; Inayathullah, M.; Zhuge, Y.; Rajadas, J. PEG/ Dextran Double Layer Influences Fe Ion Release and Colloidal Stability of Iron Oxide Nanoparticles. Sci Rep. 2018, 8, 4286.

(53) HØYER, K. Physiologic variations in the iron content of human blood serum. 1. The variations from week to week, from day to day and through twenty four hours. Acta Med. Scand. 1944, 119, 562576.

(54) Lu, W.; Zhao, M.; Rajbhandary, S.; Xie, F.; Chai, X.; Mu, J.; Meng, J.; Liu, Y.; Jiang, Y.; Xu, X.; Meng, A. Free iron catalyzes oxidative damage to hematopoietic cells/mesenchymal stem cells in vitro and suppresses hematopoiesis in iron overload patients. Eur. J. Haematol. 2013, 91, 249-261.

(55) Fajtova, M.; Kovarikova, A.; Svec, P.; Kankuri, E.; Sedlak, J. Immunophenotypic profile of nucleated erythroid progenitors during maturation in regenerating bone marrow. Leuk. Lymphoma 2013, 54, 2523-2530.

(56) Macrì, S.; Pavesi, E.; Crescitelli, R.; Aspesi, A.; Vizziello, C.; Botto, C.; Corti, P.; Quarello, P.; Notari, P.; Ramenghi, U.; Ellis, S. R.; Dianzani, I. Immunophenotypic Profiling of Erythroid Progenitor Derived Extracellular Vesicles in Diamond Blackfan Anaemia: A New Diagnostic Strategy. PLoS One 2015, 10, e0138200.

(57) Liu, S.; McConnell, S. C.; Ryan, T. M. Erythropoiesis in the absence of adult hemoglobin. Molecular and cellular biology 2013, 33, $2241-2251$ 
Karlsruher Institut für Technologie

\section{Repository KITopen}

Dies ist ein Postprint/begutachtetes Manuskript.

Empfohlene Zitierung:

Brändle, K.; Bergmann, T. C.; Raic, A.; Li, Y.; Million, N.; Rehbock, C.; Barcikowski, S.; LeeThedieck, C.

Iron Nanoparticle Composite Hydrogels for Studying Effects of Iron Ion Release on Red Blood Cell in Vitro Production.

2020. ACS applied bio materials, 3.

doi:10.5445//R/1000125240

Zitierung der Originalveröffentlichung:

Brändle, K.; Bergmann, T. C.; Raic, A.; Li, Y.; Million, N.; Rehbock, C.; Barcikowski, S.; LeeThedieck, C.

Iron Nanoparticle Composite Hydrogels for Studying Effects of Iron lon Release on Red Blood Cell in Vitro Production.

2020. ACS applied bio materials, 3 (8), 4766-4778.

doi:10.1021/acsabm.0c00297 